\title{
Lifecycle Information Systems: the concept, principles and an approach
}

\section{Sergio Evangelista Silva', Filipe Nunes Ribeiro ${ }^{2}$, Rafael Ferreira Camarda ${ }^{3}$, Vicente José Peixoto de Amorim²}

Departamento de Engenharia de Produção / Instituto de Ciências Exatas e Aplicadas Universidade Federal de Ouro Preto (UFOP), João Monlevade, Minas Gerais - Brasil

Departamento de Computação e Sistemas de Informação / Instituto de Ciências Exatas e Aplicadas - Universidade Federal de Ouro Preto (UFOP), João Monlevade, Minas Gerais - Brasil

\author{
${ }^{3}$ Locaweb Serviços de Internet SA / São Paulo, São Paulo - Brasil \\ sergio.silva@ufop.edu.br, filiperibeirobregmail.com, \\ rf.camarda@gmail.com, vjpamorimegmail.com
}

\begin{abstract}
The aim of this article is to introduce the concept of lifecycle information systems (LCISS), in which the main purpose is to permit the development of ISs capable of supporting the management of information of an entity during its whole lifecycle. In order to validate this concept, we outline the MyHistory which consists in an experimental IS structured in four different contexts, supporting the information management of persons during their lifecycle. As the main contribution, this article introduces a new approach for the development of ISs which can improve the current way of information management of entities.
\end{abstract}

Keywords. Information systems; information management; Entity lifecycle; Cloud computing; Mobile; Wearable.

\section{Introduction}

Nowadays, the development of information systems (ISs) rely on a perspective focused on the organization [Flet, 2012; Sinderen \& Almeida, 2011; Hullavarad, Hare \& Roy, 2015]. As a consequence all information about an entity (e.g. a car, a person, a building, a project, and so on) generated during its lifecycle is normally stored in several ISs of different organizations. This approach leads to following drawbacks: it is costly for an actor to gather all information available about a given entity generated during its lifecycle in different organizations; it is likely finding out data inconsistency about the same entity between the ISs of different organizations; actors (persons and organizations) are very dependent of different organizations (e.g. hospitals, schools, public bureaus;...) which own their data, when they want to access them.

Despite the above-mentioned drawbacks, some applications which support the management of information of entities at their lifecycle have been developed [Azevedo, Faria \& Ferreira, 2017; Ferreira, Faria, Azevedo \& Marques, 2017; Hedberg, Feeney, Helu \& Camelio, 2017]. However, these approaches still perform this task based on organizational and proprietary perspectives, lacking the support for the information management of a given entity which outperforms the boundaries of a particular 
organization or context. An exception to this is Kauxhik \& Raman [2015] that introduces the development of a IS capable of manage health information, in a unique single repository, which can be managed by different organizations.

Innovative products in many times can arise from the combination of different technologies. But, this situation will only occurs since it is possible generates new mindsets and conceptual models to provide guidance for new ways of combining the available technologies [Azevedo, Faria \& Ferreira, 2017; Maass \& Varshney, 2012; Pang et al., 2015; Kim \& Kim. 2012]. In this sense, the arising of technologies such as internet of things (IoT), mobile and cloud computing [Bayramusta \& Nasir, 2016; Newman, Chang, Walters, \& Wills, 2016; Pang et al., 2015], permit the development of ISs which bypass the organizational boundaries, as well as, allow the management of information at the lifecycle of a given entity.

In spite of the development of some approaches to support the information management of an entity during its lifecycle, these approaches are still at the beginning of the full potential of exploration of this type of ISs. Thus, it is still necessary the development of a paradigm which relying on a set of premises is capable of providing a new perspective to the development of such ISs. In this vein, the purpose of this article is to introduce the concept of lifecycle information systems (LCISs) and propose a set of principles to the development of this type of ISs. This conceptual model is validated through the development of the MyHistory which the purpose is to support the management of information of persons, during its life. For attaining this goal, this IS encompasses different contexts and sub-contexts to adequately allow the information management.

This new conceptual paradigm in the IS realm opens new avenues for the development of ISs capable to manage information of entities in a level not reached yet. Additionally, the LCISs point out to the necessity of guarantee the integration of information in a universal perspective, that is, that all information of an entity can be stored in a unique repository which transcends a particular organization.

\section{Literature Review}

\subsection{Organizational focused Information Systems}

The majority of IS literature is dedicated to issues related to the application of ISs in the organization. From a historical perspective, the first IS arise with the purpose of support the execution of operations in the organizational silos, where it was common the replication of the data of the same entity in several ISs available within the organization, dedicated to supporting each specific functional area or department. These systems were termed as legacy systems, and due to no integration of their information, they typically generated problems as high costs to manage the whole dataset of the organization and information inconsistency, which refers to the situation where there are different and incompatible information about the same state of an entity [Dunn Jr., Cobb, Levey, \& Gutman, 2016; Arvidsson, Holmstrom, \& Lyytinen, 2015; Hisham et al., 2015; Fu, 2016].

The information inconsistency and the costs of maintaining different ISs in the same organization have been overcome with the development of ISs named as Enterprise Resource Planning (ERP) [Marnewick \& Labuschangne, 2005; Sammon \& Adam, 2005]. Accordingly, the ERPs have incorporated the business process rationale [Koch, 2001]. In 
this way, the ERP "breaks" the departmental barriers, permitting an integrated view of the several everyday tasks performed in the organization, which is focused on the various activities required to produce a given output. Though, as the legacy systems, as well as ERPs are dedicated to manage structured information in an organizational point of view [Abraham, Junglas, Watson, \& Boudreau, 2016; Flett, 2012].

A step in the continuous integration of organization happens when the ISs dedicated to managing the main datasets of the organizations are integrated with ISs focused on specific tasks [Hedberg, Feeney, \& Helu, 2017] in order to collect data from real-time operations of the organization, through the use of sensors, and other devices [Arvidsson et al., 2015].

Another aspect of ISs evolution is the integration between ISs of different organizations. This type of integration has as main goal to permit the interchange of information between organizations [Kee-Hung, Wong, \& Cheng, 2008]. More recently, with the emergence of cloud computing, it is unfolding the development of ISs which allow the information management process of an organization by ISs operating remotely at the cloud spaces [Ren et al., 2015; Hashem et al., 2016; Bayramusta \& Nasir, 2016].

According to the several steps of evolution of ISs reported above, one can be noted that the emphasis of these ISs is on supporting the everyday managerial and operational issues of organizations. As a result, these systems normally do not provide functionalities such as the traceability of an entity (e.g. a product or a customer) whereas it is out of the boundaries of a given organization. Likewise, these systems normally also do not allow the management of multiple types of information (structured, textual documents, multimedia, ...), about these entities.

\subsection{New information and communication technologies}

The advent of new technologies has posed new possibilities for the development of ISs. As mentioned earlier the cloud computing consists of the development of ISs which permit the whole process of information management from a remote space, which can be maintained by a third party [Ren et al., 2015; Hashem et al., 2016; Bayamusta \& Nasir, 2016]. This technology allows the development of innovative applications in different fields such as health care [Pang et al., 2015; Zhou et al., 2016] manufacturing and management [Ren et al., 2015], among others [Hashem et al., 2016; Ing, Jagstaidt, Kossahl, \& Kolbe, 2011; Newman et al., 2016].

Currently other important technology is the mobile computing. The huge amount of mobile devices and their portability allow new possibilities to collect and exchange information in a fine-grained level. In other words, mobile computing has allowed pervasiveness in data generation and collection [Maass \& Varshney, 2012]. For this huge potentiality, mobile computing has been used in many situations such as marketing services [Berman, 2016], at work [Chatterjee, Sarker, \& Siponen 2017; Ding et al., 2014], at health care [Klasnja \& Pratt, 2012; Pang et al., 2015] and so on.

Additionally, the concept of the Internet of Things (IoT) presents the ambitious desire of embed in several concrete objects applications that should be connected to the internet [Pang et al., 2015; Domingo, 2012]. In this context, a relevant technology is the wearable, which consists of the use of monitoring devices and sensors coupled with a body or other object to obtain some kind of information from it. Currently, this technology is much used in the context of health care information systems [Sultan, 2015; Pang et al., 2015]. 
Accordingly, these three different technologies present new opportunities to the development of ISs capable of employing more powerful mechanisms of data collection, as well as the capacity of reaching the highest level of information consistency, whereas they should be implemented in a perspective which transcends the view focused in a single organization.

\subsection{Current ISs with Lifecycle Approaches}

Besides the predominant approach of ISs focused on the organizational perspective, recently has emerged a new rationale about ISs focused on the support of the information management of a given type of entity, during its lifecycle. From the viewpoint of organizations, these approaches can be classified into three main types, namely, focused on: i) - the organizational context; ii) - the inter-organizational context; iii) - transcending the organizational boundaries. These ISs are described below and its main aspects resumed in Table 1 .

At the organizational context, the information management of an entity involves the development of ISs capable of managing multiple data types and gathers them in a unique repository. For instance, Ferreira et al. [2017] outline the development of a IS capable of managing information of projects, in the context of the automobile industry. In this vein, Hedberg et al. [2017] introduce a conceptual framework for the development of ISs for supporting the management of information of products during its entire lifecycle within the firm.

In an inter-organizational manner Azevedo et al. [2017] propose a framework for managing virtual manufacturing, allowing the complete information management of a given project performed by a group of firms. Regarding this, there are presented some recent approaches in the health context, which the purpose is to integrate health information between different organizations [Constantinescu, Kim \& Feng, 2012; Li et al., 2008].

ISs which transcend the organizational boundaries are those which are not attained to a specific organization, or group of organizations. Additionally, this type of ISs has a virtually unique database which concentrates all information about one given type of entity, providing what can be named as universal data consistency. This type of approach is showed at Kauxhik \& Raman [2015] who describe an IS which the purpose is to integrate the health data of a huge population in an Indian state. This IS operates independently of health agents (hospitals, public agents,...) concentrating in a unique virtual repository the health information of citizens who reside in this state.

In addition, in the context of management of personal information, recently there were developed ISs which the function is to manage some aspect of the person's life, as digital memories [Dobbins, Madjid, Fergus, \& Llewellyin-Jones, 2014], archives (Guldenpfenning \& Fitzpatrick, 2015) and self-control of diabetes [Ayatollahi et al., 2016]. Still, in this perspective, the personal e-mail accounts provided by e-mail provider services can be considered as the most used IS approach focused on the management of lifecycle information about personal messages. Though, these services provide support only to the control of messages. Despite these e-mail services allow the exchanging of digital documents, it is carried out in an informal way, lacking proper management of all information of an individual during its entire lifecycle, nor allowing a fine-grained management of information based on contexts, what is the purpose of the IS approach proposed in this article. 
Table 1. Types of current ISs which permit information management in the lifecycle of an entity

\begin{tabular}{|c|c|c|}
\hline $\begin{array}{l}\text { Type of } \\
\text { Current LCISs }\end{array}$ & Main issues & References \\
\hline $\begin{array}{l}\text { Organizational } \\
\text { LCISs }\end{array}$ & $\begin{array}{l}\text { Controlled by only one organization } \\
\text { Control the lifecycle of a given type of entity within the } \\
\text { context of an organization } \\
\text { Manage the information of an entity which is interest } \\
\text { of the organization }\end{array}$ & $\begin{array}{l}\text { Ferreira et al. (2017); } \\
\text { Hedberg et al. (2017) }\end{array}$ \\
\hline $\begin{array}{l}\text { Inter- } \\
\text { organizational } \\
\text { LCISs }\end{array}$ & $\begin{array}{l}\text { The IS is generated through the alliance among } \\
\text { organizations } \\
\text { It is controlled by the group of organization which } \\
\text { comprehend the alliance }\end{array}$ & $\begin{array}{l}\text { Azevedo et al. (2017); } \\
\text { Constantinescu et al. } \\
\text { 2012; Li et al. (2008) }\end{array}$ \\
\hline $\begin{array}{l}\text { Trans- } \\
\text { organizational } \\
\text { LCISs }\end{array}$ & $\begin{array}{l}\text { The IS is controlled by a third party which offers this } \\
\text { service for organizations and/or persons } \\
\text { IT manages the information of an entity which the } \\
\text { interest is of organizations and persons abroad which } \\
\text { are associated with its generation } \\
\text { Persons have direct access to their own information; } \\
\text { The IS reach data consistency in a level which } \\
\text { transcends the organization }\end{array}$ & $\begin{array}{l}\text { Kauxhik \& Raman } \\
\text { (2015); } \\
\text { Dobbins et al. (2014); } \\
\text { Guldenpfenning \& } \\
\text { Fitzpatrick (2015) }\end{array}$ \\
\hline
\end{tabular}

Accordingly, it is noteworthy that the management of information about a given entity during its entire lifecycle will imply in the management of multiple types of documents [Azevedo et al., 2017; Ferreira et al. 2017; Hedberg et al. 2017]. Additionally, the entire life cycle of an entity normally involves the generation of data in different contexts where this entity will interact with others entities and generate new information [Fu 2016; Hedberg et al. 2017; Pang et al. 2015]. Thus, it is necessary to consider the necessity to develop ISs capable of support the manipulation of information of entities during its whole lifecycle, permitting the manipulation of different types of documents in different contexts.

\section{Method}

This article uses predominantly the theoretical approach, where the concept of LifeCycle information systems is in part deducted from the current ISs approaches. As well as other theories developed in the literature [Chatterjee et al. 2017; Chao; Kavadias, 2008], the purposed model has the objective of orientate the development of ISs in lights of absolute information lifecycle management. The concept of LCISs attempt to generalize the concept of lifecycle information to the different objects of the reality. Additionally other important concept used in the context of LCISs is the multi-contextual data modeling which permit to manage information of multiple contexts related to a same object [ERFANI et al., 2016]. 
Other methodological subject of the theoretical model purposed is the set of guidelines related to the concept of LCISs, which also is based on the deductive logic, in part based on the literature review.

\subsection{The empirical validation}

In order to validate the purposed concept of LCISs it was implemented MyHistory which is experimental ISs whose the purpose is to permit the information management of person across their lives. In such, it is an experimental case study with the purpose of text a theory [EINSENHARDT, 1989; Yin, 1994].

This ISs was implemented in a multi-contextual form allowing the management of information with different formats and subjects. MyHistory was implemented based on the set of LCISs principles which will be presented in the next section.

The first step to the implementation of MyHistory was the modeling of the data and functionalities of the system, which will be described in the fourth section. As such, this IS permit to validate the concept of LCIS which is the main focus of this paper. The validation event with the laboratorial scale permit to deduct which this type of IS's approach is viable to support data of different types of entities, such as humans, buildings, cars, general appliances, and so on.

\section{The principles of Lifecycle Information Systems}

Even though it was described above some ISs approaches capable of supporting the information management at the lifecycle of an entity. To the best of our knowledge, it is not defined group of principles about the development of ISs focused on supporting the information management in the whole lifecycle of an entity, guarantying the manipulation of multiple data formats, semantically organized, in a trans-organizational way, which results in the universal data consistency and access. The ISs capable of providing these properties will be termed as lifecycle information systems (LCISs).

Firstly, it is necessary to better conceptualize LCISs, which refers to a type of IS capable of supporting the management of information of a given type of entity (e.g. persons; animals; automobiles; buildings; equipment;....) in its whole lifecycle. The basic purpose of these ISs is to gather all information (structured data, textual documents, files, images, and so on) about an entity, semantically ordered in a unique information repository.

As such Figure 1 presents a representation of a LCISs to support the management of information of persons during their lifecycle. In this figure the LCIS operates in a cloud space and acts intermediating the relations of persons with different types of organizations (schools, government, hospital,...) 


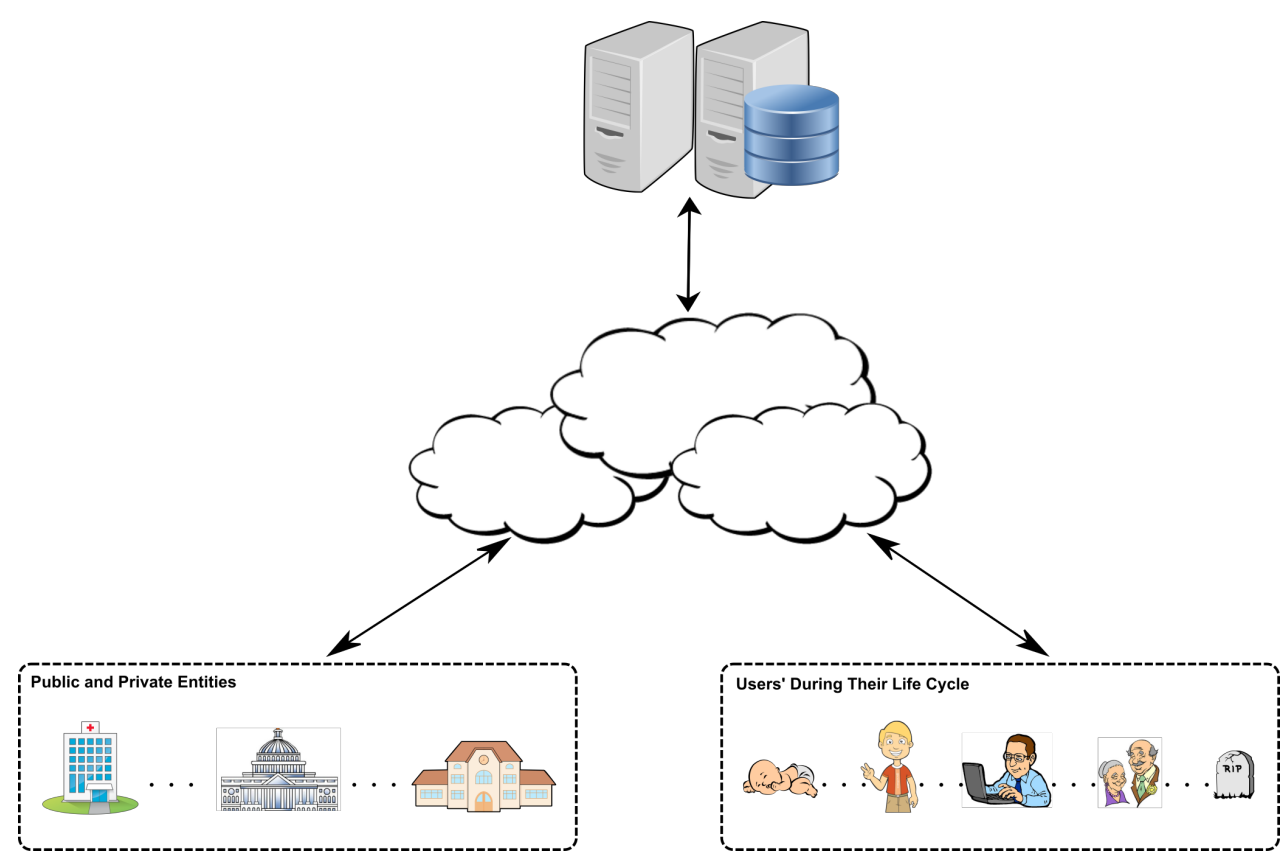

Figure 1. An allusion to a LCIS to support information management of persons during their lifecycle.

Additionally, in this section we present a set of issues which we believe will enable the development of LCISs. Accordingly, there are proposed three layers of scope for these systems, namely, infrastructure, information system and information management, presented below.

\section{a) - LCISs' Infra-structure}

This construct refers to the basic hardware and software framework capable of support the development of LCISs, regarding aspects as data processing, storage, and communication.

Cloud Computing Use: The cloud computing technologies [Ren et al. 2015; Hashem et al., 2016; Bayamusta \& Nasir, 2016] should be the basic infrastructure elements in the development of LCISs. These technologies are necessary to guarantee the development of a central software with an information repository, which is fundamental in the process of information gathering, storage and recovering.

Computing Framework: It is required that a central system available in a cloud server, manage all information about a given type of entity and communicate with apps running remotely in mobile [Klasnja \& Pratt, 2012; Pang et al., 2015] and internet of things devices (Pang et al., 2015; Domingo, 2012), including wearable ones [Sultan, 2015].

\section{b) - LCISs' Information System Approach}

This construct refers to how the information will be logically manipulated and stored.

Information management focused on a given type of entity: As the name suggests, a LCISs' have to be deployed to support the information management of only one given 
type of entity. Thus, some entities whose can be developed ISs according to the LCISs logic are persons, automobiles, ships, airplanes, buildings, public projects, animals, food, among others.

Central software: It is necessary the development of a centralized software capable of managing the information of a given type of entity, maintaining its universal data consistency. Additionally, this software should be capable of communicating with other applications.

Unique database: Regarding the prior examples of entities who is possible the development of LCISs', one can be noticed that their process of information generation transcends the particular organizations. For instance, a person during his entire life can generate information in different hospitals, government bureaus, schools, jobs and so on. Thus, development of a LCISs' to give support to the information management of person should not be restricted to one organization, except that which will provide this system. In this vein, to manage information about entities during their whole lifecycle the data of an entity should be stored in a virtually unique database, for further access of this entity and the organizations which it will have some relation.

Multiple data formats: LCISs may give support for the management of multiple types of information (textual documents; structured; images; video; real-time data, and so on), once it will be generated different types of documents and information across the lifecycle of an entity.

Interoperability: LCISs should be prepared to communicate with ISs of different organizations, wherein most of the information generated by an entity during its whole lifecycle will take place due his contact with different organizations.

\section{c) - LCISs' Information management}

Universal data consistency: In a situation that all information of an entity will be gathered in a unique point, and it will be guaranteed that for each piece of information exists only one file, it will be possible to reach the total data consistency. This situation will be reached because of the elimination of replication of information about the same entity;

Information access grant, maybe information transfer: Nowadays, due to the replication of the same information of an entity between different organizations, a common practice is the transference of information through files, between persons and organizations, which implies in a continuous and indefinite process of information replication. In a situation, where all information about a given entity is stored in a unique database, there is no need to perfom information transference. Rather, in this situation, maybe transfer information, the agents will grant access to an information which is stored in an unique data space;

Information Pertaining to the Own Person: Currently the information of persons are possessed by the organization which they have some type of relationship during their 
lives. For instance, if a person needs documents about his professional career. Instead he has stored all documents along his career, he should to seek to all organizations where he worked to gather documents about it. On the other hand, in the context of LCISs, considering a IS developed to gather all information about persons, the recovering of these documents can be made directly by the person, as well as he access this mentioned IS.

Multi-contextual management of Information: Along with its entire lifecycle an entity will generate information in varied contexts (e.g. a person will relate to health, civil, work, educational contexts, inter alia). Thus, the LCISs should be able to manage information in different contexts but organized in a unique structured database.

Trans-organizational approach: In sum, the development LCISs will require that these systems will be able to receive information and grant access to ISs of different organizations. Thus, it is necessary an approach to information management which transcend particular organizational contexts. However, such approach has to be prepared to deal with different organizations, receiving information and providing access to information, although it has not been dependent on a particular organization.

\section{MyHistory, A LCIS for the for management of personal information}

In this section, we will present an instance of a LCIS, deployed in an experimental manner which the purpose is to validate the principles proposed in the prior section. The purpose of the MyHistory is to support the whole information management process across the lifecycle of a person.

\subsection{MyHistory architecture}

Initially MyHistory was implemented to supporting four contexts of a person's life, namely education, health, civil and financial contexts, outlined in Figure 2.

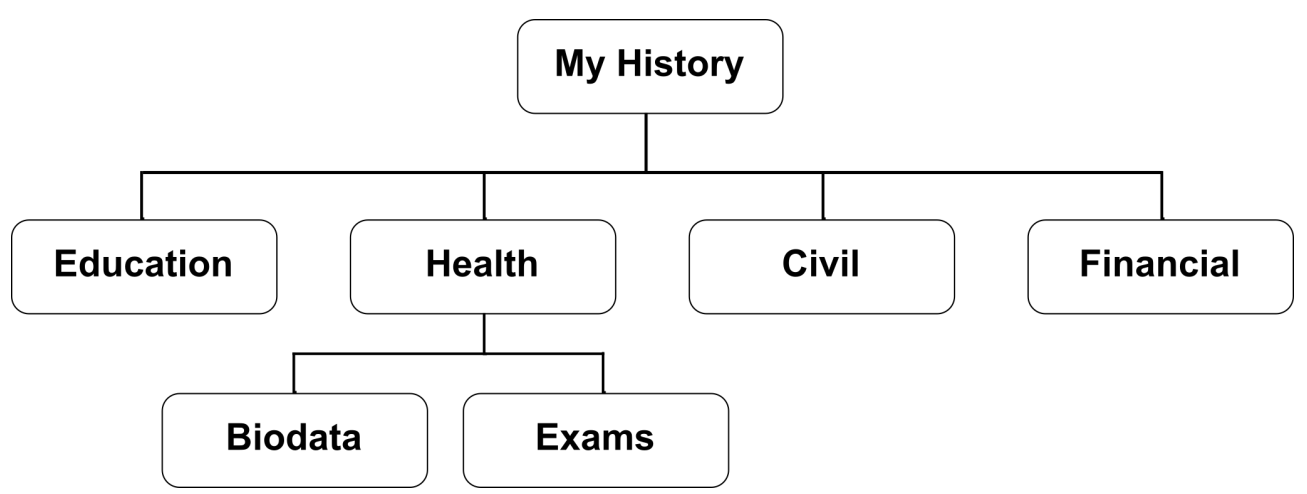

Figure 2: Initial contexts and subcontexts considered by MyHistory. 
At the civil context, the purpose is supporting the user load personal documents, for grant further access permission for organizations which a person will relate. Make part of this contexts identification documents as the identity card, birth certificate, current address and so on. The financial life of an adult person can be typically very ample, encompassing transactions in many situations. Due to this, in the financial context was provided a sub context which the aim is to permit to a user receiving the documents which prove the payment of a given bill. The educational context permits a person to load or receive educational certificates and diplomas. Lastly, it was implemented the context named as Health which provides the sub-contexts Biodata and Medical Exams. The Biodata, which the interface is presented in Figure 3, was implemented with the purpose of receiving real-time data accruing from a wearable device that can be attached to the user in the sense of monitor issues such as blood pressure, heartbeats and blood glucose index (for diabetes monitoring see Ayatollahi et al. [2016]. The second sub context, Exams has the purpose of receiving medical exams of the user, realized in clinical laboratories.

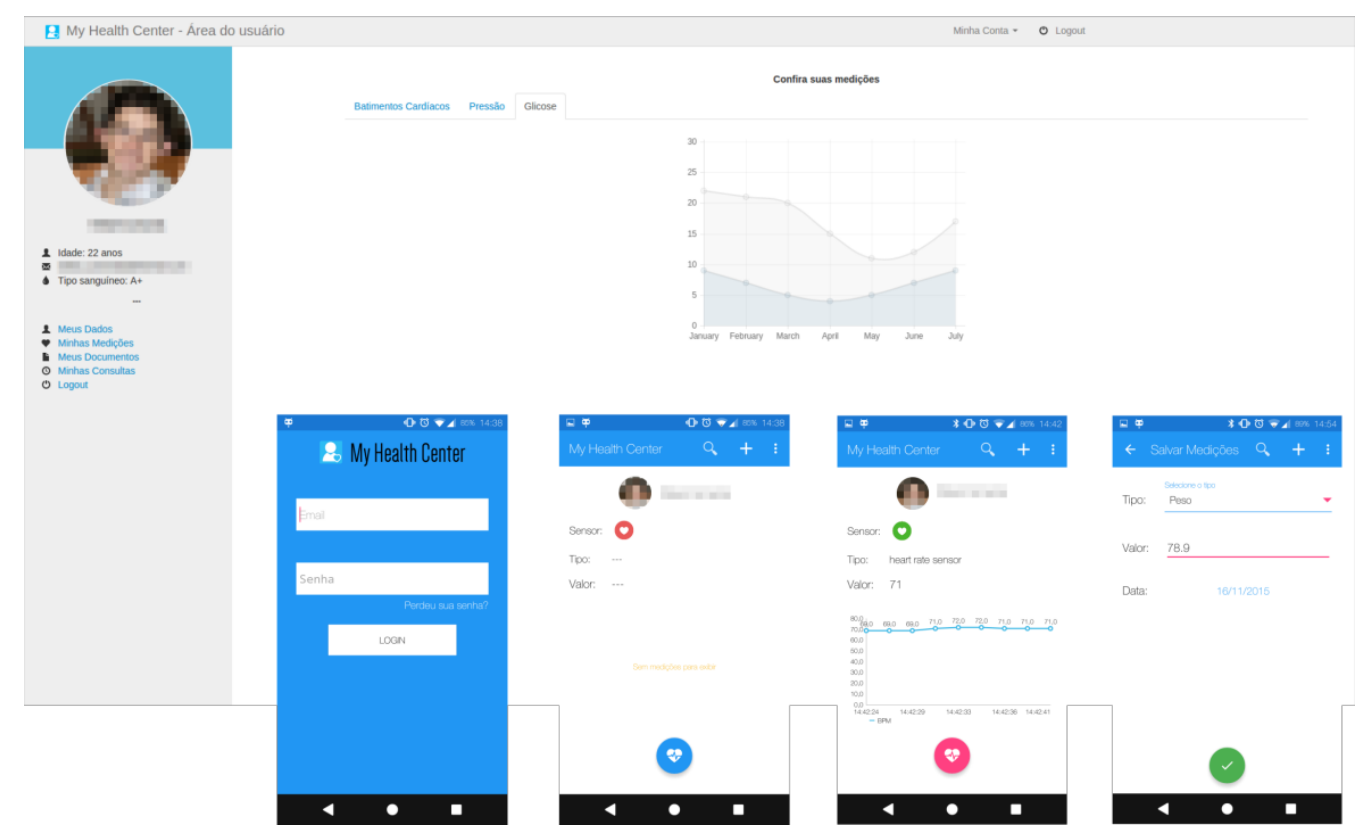

Figure 3. The interface of the biodata module with real-time data.

\subsection{MyHistory Infra-Structure and IS approach}

Although deployed in an experimental way the concept of MyHistory assumes that is possible to support all information management process of a person during his entire life long. Accordingly, this system was implemented within a unique database. As a database it was used a relational database management system, to store basic data of a person, as well as a space to store personal documents.

Figure 4 depicts how the information is managed inside MyHistory. Initially data is gather from related devices (smartphones, tablets, fitness devices, ...) or manually inserted by the users or public and private entities. That information is stored in remote servers, working as virtual databases available through a cloud infrastructure. Finally, data previously generated may be accessed back by the final users or even by the same entities. 


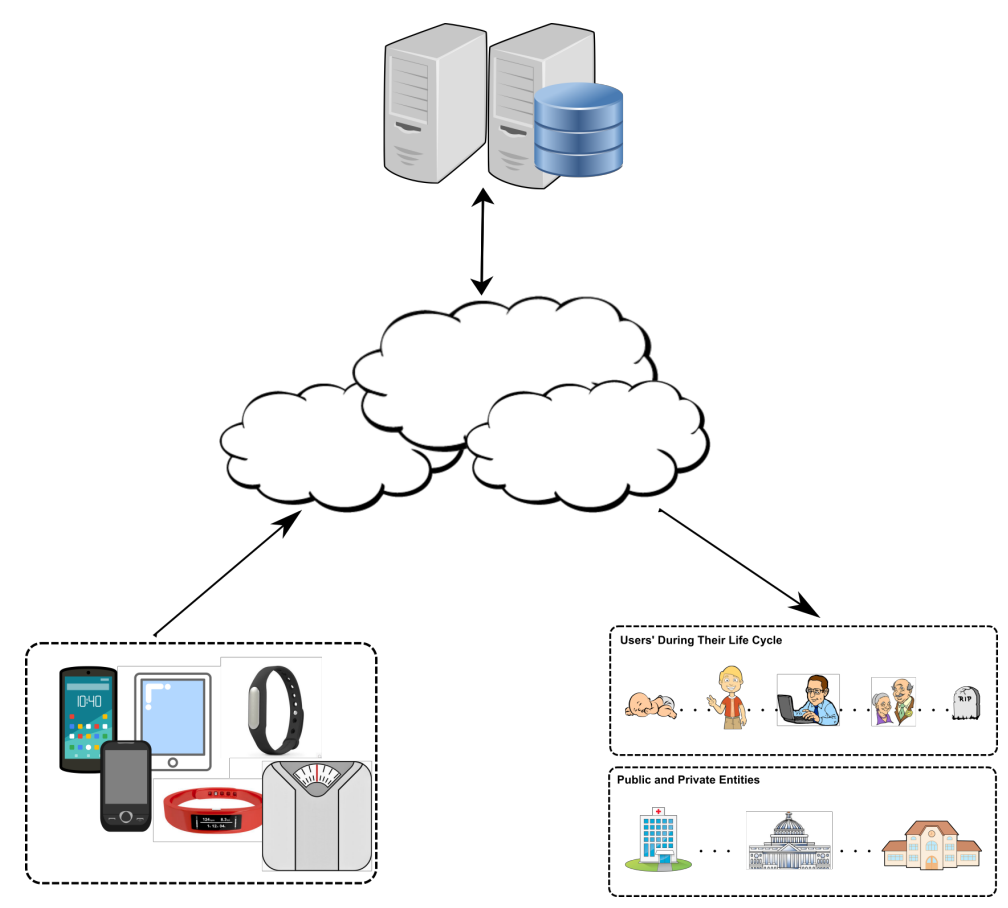

Figure 3: Data flow inside MyHistory architecture.

Due to the generation of data in multiple contexts and formats, the MyHistory receives structured data types about users, and information about the user's physical situation. This information is stored in a structured database manner, allowing the restoring of data plotted in historical graphics. Besides this structured information, this IS also receive information registered in textual documents (personal documents, payment recipes, and medical exams), which is in .pdf format.

The contexts are management by only one IS implemented in Java and PHP/JavaScript programming languages. However, its software interoperates with others, which operates in mobile phones, and in wearable devices, which the purpose is to collect biophysical information about users.

\subsection{MyHistory Information management approach}

Concentrating personal information of citizens (e.g. personal documents; receipt of payment and so on) within a unique database MyHistory provides what is defined as universal data consistency. Imagining that the user can stor its current home address in the system, and that a person during its entire life normally will change his address, and in many organizations he will register its actual address, the use of this register in the MyHistory will prevent data inconsistency, as well as, the organization ever would have access to his updated address. Thus, the universal data consistency presumes a central database which guarantees the information validity.

Whereas information refers to the meaning of the status of some fact (object or an activity) in a given moment, it is desirable that there is only an information register to each status. In practice, due to technological limitations and moreover, the organizational limitations, it is common the existence of the duplication of information about the same object. However, the basic assumption of MyHistory about concentrating all information 
of a person in a unique database will eliminate the information duplication. In this situation is more feasible the permission of access to a given information. For instance, when a person registers an account in some organization, the supplying of his personal documents (e.g. identity card, address, etc) can be performed by a permission of access to these personal documents through the MyHistory, maybe present paper documents or send digital ones by e-mail. In sum, the permission of access of data is more efficient than sending them to e-mail because it prevents data replication, and avoids future data inconsistency, as well as, the information about some entity change its status.

Although the MyHistory comprehend only four contexts, seemingly an IS which the purpose is to support the information management of a person at his whole lifecycle will require the implementation of more contexts, with a more deep framework of subcontexts.

\section{Analysis and Conclusions}

This paper introduces the concept of information management at the whole lifecycle of an entity and the development of ISs capable of attaining this objective. Owing to the present it is still predominant ISs approaches focused on the management of information in an organizational perspective. As consequence, the most of the information of many entities such as persons, cars, properties, among others are nowadays under the control of organizations, being of difficult access of citizens.

This paper presents a new rationale for the development of ISs, as well as information management which approaches this drawback. As consequence, its main contribution is to present the main concepts about the development of LCISs. Additionally, other important insights like as universal data consistency, the concentration of all information of an entity in a unique information repository, the management of information in varied formats and within multiple contexts are also presented, what permit the envisioning of the huge impact that the adoption of the concept of LCIFs can have in future of information management.

As validation of the concepts presented it was developed in the experimental and laboratory scale the MyHistory, which consists of an IS destined to support the entire information management of a person during its lifecycle. Although it was presented only a few quantity of contexts, in face of all possibilities of contexts possible about a lifecycle of a person, MyHistory suggests that is feasible the development of LCISs in the near future for manage information of different types of entities.

However, it is necessary to note that the development of LCISs will pose many challenges in different fields. From a technical perspective the development of such systems will demand improvements in the database modeling and development theory. Additionally, in the aspects of information security, it is great the damage of improper access to the information of an entity, whereas security issues are critical to this type of ISs, so as to ensure information privacy and safety.

Lastly, the development of LCISs poses many social challenges. While the development of this type of ISs can account to the entrepreneurship of entrepreneurs and firms which envisage this type of systems as a profitable task, the use of these systems will depend on the collaboration of different organizations. Another aspect is the changing logic of information control from the organizational perspective to the person perspective, which can motivate resistance of some organizations in collaborate to releasing information of entities, due to the preemption of power lost due to the loss of control of 
information. From the rest, the development of such systems will require firstly the development of information governance patterns and agreements in the sense of leverage the interests of multiple agents which will engage in the development and use of LCISs.

\section{References}

Azevedo, A., Faria, J., \& Ferreira, F. (2017). Supporting the entire life-cycle of the extended manufacturing. Robotics and Computer-Integrated Manufacturing, 43, 2-11. doi: https://doi.org/10.1016/j.rcim.2016.05.009; [[GSSEARCH].

Abraham, C., Junglas, I., Watson, R. T., \& Boudreau, M. C. (2006). Explaining the unexpected and continued use of an information system with the help of evolved evolutionary mechanisms. Journal of the Association for Information Science and Technology, 67(1), 212-231. doi: https://doi.org/10.1002/asi.23344; [GSSEARCH]

Arvidsson, V., Holmstrom, J., \& Lyytinen, K. (2015). Information systems use as strategy practice: a multi-dimensional view of strategic information systems implementation ad use. Journal of Strategic Information Systems, 23, 45-61.

doi: https://doi.org/10.1016/j.jsis.2014.01.004; [GSSEARCH]

Bayramusta, M., \& Nasir, V. A. (2016). A fado or future of IT? A comprehensive literature review on the cloud computing research. International Journal of Information Management, 36, 635-644. doi: https://doi.org/10.1016/j.ijinfomgt.2016.04.006; [GSSEARCH]

Berman, B. (2016). Planning and implementing effective mobile marketing programs. Business Horizons, 59, 431-439. doi: https://doi.org/10.1016/j.bushor.2016.03.006; [GSSEARH]

Chatterjee, S., Sarker, S., \& Siponen, M. (2017). How do mobile ICTs enable organizational fluidity: toward a theoretical framework. Information and Management, 34, 1-13. doi: https://doi.org/10.1016/j.im.2016.03.007; [GSSEARCH]

Chao, R. O.; Kavadias, S. (2008). A theoretical framework for managing the new product development portfolio: when and how to use strategic buckets. Management Science, 54(5), 907-921. https://doi.org/10.1287/mnsc.1070.0828; [GSSEARCH].

Constantinescu, L., Kim, J., \& Feng, D. (2012). SparkMed: A Framework for Dynamic Integration of Multimedia Medical Data into Distributed m-Health Systems. IEEE Transactions on Information Technology in Biomedicine 16(1), 40-52.

doi: https://doi.org/10.1109/TITB.2011.2174064; [GSSEARCH]

Chatterjee, S.; Sarker, S.; Siponen, M. (2017). How do mobile ICTs enable organizational fluidity: toward a theoretical framework. Information and Management, 34, 1-13. https://doi.org/10.1016/j.im.2016.03.007; [GSSEARCH].

Domingo, M. C. (2012). An Overview of the Internet of Things for People with Disabilities. Journal of Network and Computer Applications 35(2), 584-596. doi: https://doi.org/10.1016/j.jnca.2011.10.015; [GSSEARCH] 
Dobbins, C., Madjid, M., Fergus, P., \& Llewellyin-Jones, D. (2014). Creating human digital memories with the aid of pervasive mobile devices. Pervasive and Mobile Computing, 12, 160-178. doi: https://doi.org/10.1016/j.pmcj.2013.10.009; [GSSEARCH]

Dunn Jr., Cobb,J., Levey, A. I., \& Gutman, D. A. (2016). Redletr: workflow and tools to support the migration of legacy clinical data capture systems to REDCap. International Journal of Medical Informatics, 93, 103-110. doi: https://doi.org/10.1016/j.ijmedinf.2016.06.015; [GSSEARH]

Ding, J. H., Chien, H. R. S., Lin Y.; Kuo, C., Hsu, C., \& Chung, Y. (2014). A framework of cloud-based virtual phones for secure intelligent information management. International Journal of Information Management, 34, 329-335.

doi: https://doi.org/10.1016/j.ijinfomgt.2013.11.006; [GSSEARCH]

Ferreira, F., Faria, J., Azevedo, A., \& Marques, A. L. (2017). Product lifecycle in knowledge intensive collaborative environments: an application to automobile industry. International Journal of Information Management, 37, 1474-1487. doi: https://doi.org/10.1016/j.ijinfomgt.2016.05.006; [GSSEARH]

Einsenhardt, K. M. (1989). Building theories from case study research. The Academy of Management Review, 14(4), 532-550. https://doi.org/10.5465/AMR.1989.4308385; [GSSEARCH].

Erfani, M.; Zandi, M.; Rilling, J.; Keivanloo, I. (2016) Context-awareness in the software domain: a semantic web enabled modeling approach. The Journal of System and Software, 121, 345-357. https://doi.org/10.1016/j.jss.2016.02.023; [GSSEARCH]

Flett, A. (2012). Information Management Possible? Why is information management so difficult? Business Information Review, 29,111-120. doi: https://doi.org/10.1177/0266382111411066; [GSSEARCH]

Fu, G. (2016). FCA based ontology development for data integration. Information Processing and Management, 52, 765-782. doi: https://doi.org/10.1016/j.ipm.2016.02.003;

\section{[GSSEARCH]}

Guldenpfenning, F., \& Fitzpatrick, G. (2015). Personal digital archives on mobile phones with MEO. Personal Ubiquitous Computing, 19, 445-461. https://doi.org/10.1007/s0077; [GSSEARCH]

Hashem, I. A. T., Chang, V., Anuar, N. B., Adewole, K.; Yaqoob, I., Gani, A., Ahmed, E., \& Chiroma, H. (2016). The role of big data in smart city. International Journal of Information Management, 36, 748-758. [GSSEARCH]. doi: https://doi.org/10.1016/j.ijinfomgt.2016.05.002.

Hedberg, Jr., T. Feeney, A. B., Helu, M., \& Camelio, J. A. (2017). Toward a lifecycle information framework and technology in manufacturing. Journal Computing and Information Science in Engineering, 17(2), 1-13. doi: https://doi.org/10.1115/1.4034132. [GSSEARCH]

Hullavarad, S., O'Hare, R., \& Roy, A. K. (2015). Enterprise content management solutions - roadmap strategy and implementation challenges. International Journal of Information Management, 35, 260-265. doi: https://doi.org/10.1016/j.ijinfomgt.2014.12.008; 


\section{[GSSEARCH].}

Ing. D. W., Jagstaidt, U. C. C., Kossahl, J., \& Kolbe, L. M. (2011). Smart metering information management. Business Information Systems Engineering, 3(5), 323-326.

\section{[GSSEARCH]}

Kauxhik, A., \& Raman, A. (2015). The new data-driven enterprise architecture for ehalthcare: lesson from the indian public sector. Government Information Quarterly, 32, 63-74. doi: https://doi.org/10.1016/j.giq.2014.11.002; [GSSEARCH]

Kee-Hung, L., Wong, C. W. Y., \& Cheng, T. C. E. (2008). A coordination-theoretic investigation of the impact of electronic integration on logistics performance. Information \& Management, 45(1), 10-20.

doi: https://doi.org/10.1016/j.im.2007.05.007; [GSSEARCH]

Klasnja, P., \& Pratt, W., (2012). Healthcare in the Pocket: Mapping the Space of MobilePhone Health Interventions. Journal of Biomedical Informatics 45(1), 184-198.

doi: https://doi.org/10.1016/j.jbi.2011.08.017; [GSSEARCH]

Kim, T.-W., \& H.-C. Kim. (2012). A Healthcare System as a Service in the Context of Vital Signs: Proposing a Framework for Realizing a Model. Computers \& Mathematics with Applications, 64 (5), 1324-1332.

\section{https://doi.org/10.1016/j.camwa.2012.03.076; [GSSEARCH]}

Li, L., Xu, L, Jeng, H. A. \& Naik, D., Allen, T., \& Frontini, M. (2008). Creation of Environmental Health Information System for Public Health Service: A Pilot Study. Information Systems Frontiers 10 (5), 531-543. doi: https://doi.org/10.1007/s10796008-9108-1; [GSSEARCH].

Koch, C. (2001). BPR and ERP: realizing a vision of process with IT. Business Process Management Journal, 7(3), .258-265. https://doi.org/10.1108/14637150110392755; [GSSEARCH]

Maass, W., \& Varshney, U. (2012). Design and evaluation of ubiquitous Information Systems and Use in healthcare. Decision Support Systems, 54, 597-609. https://doi.org/10.1016/j.dss.2012.08.007; [GSSEARCH].

Marnewick, C., \& Labuschangne, L., (2005). A conceptual model for enterprise resource planning (ERP), Information Management \& Computer Security, 13(2), 144155. https://doi.org/10.1108/09685220510589325; [GSSEARCH]

Newman, R., Chang, V., Walters, R. J., \& Wills, G. B. (2016). Web 2.0 - The past and the future. International Journal of Information Management, 36, 591-598. https://doi.org/10.1016/j.ijinfomgt.2016.03.010; [GSSEARCH]

Pang, Z., Zheng, L., Tian, J., Kao-Walter, S., Dubrova, E., \& Chen, Q. (2015). Design of terminal solution for integration of in-home health care devices and services towards the internet of things. Enterprise Information Systems, 9(1), 86-116. https://doi.org/10.1080/17517575.2013.776118; [GSSEARCH];

Sammon, D., \& Adam, F. (2005). Towards a model of organizational prerequisites for enterprise-wide systems integration: Examining ERP and data warehousing, Journal of Enterprise Information Management, 18(4), 458-470.

https://doi.org/10.1108/17410390510609608; [GSSEARCH] 
Sinderen, M., \& Almeida, J. P. A. (2011). Empowering Enterprises through NextGeneration Enterprise Computing. Enterprise Information Systems 5 (1), 1-8. https://doi.org/10.1080/17517575.2010.528802; [GSSEARCH]

Sultan, N. (2015). Reflective thoughts on the potential and challenges of wearable technology for healthcare provision and medical education. International Journal of Information Management, 35, 521-526. https://doi.org/10.1016/j.ijinfomgt.2015.04.010; [GSSEARCH].

Yin, R. K. Case Study Research: Design and methods. Second Edition, Sage Publications, 1994

Ayatollahi, H.; Hasanneszhad, M; Fard, H. S.; Haghighi, M. K.(2016) Type I diabetes self-management: developing a web-based telemedicine application. Health Information Management

Journal, 45(1), 16-26. https://doi.org/10.1177/1833358316639456;[GSSEARH] 